University of Nebraska - Lincoln

DigitalCommons@University of Nebraska - Lincoln

\title{
Age-Dependent Impairment of IgG Responses to Glycosylphosphatidylinositol With Equal Exposure to Plasmodium falciparum Among Javanese Migrants to Papua, Indonesia
}

\author{
Sarah N. Hudson Keenihan \\ University of Adelaide, sarah.hudson-keenihan@adelaide.edu.au \\ Sutanti Ratiwayanto \\ United States Naval Medical Research Unit \# 2 \\ Saraswati Soebianto \\ United States Naval Medical Research Unit \# 2 \\ Krisin \\ United States Naval Medical Research Unit \# 2 \\ Harijani Marwoto \\ Percetakan Negara No. 29 \\ See next page for additional authors
}

Follow this and additional works at: https://digitalcommons.unl.edu/usnavyresearch

Hudson Keenihan, Sarah N.; Ratiwayanto, Sutanti; Soebianto, Saraswati; Krisin; Marwoto, Harijani;

Krishnegowda, Gowdahalli; Gowda, D. Channe; Bangs, Michael J.; Frayauff, David J.; Richie, Thomas L.;

Kumar, Sanjai; and Baird, J. Kevin, "Age-Dependent Impairment of IgG Responses to

Glycosylphosphatidylinositol With Equal Exposure to Plasmodium falciparum Among Javanese Migrants to Papua, Indonesia" (2003). U.S. Navy Research. 56.

https://digitalcommons.unl.edu/usnavyresearch/56

This Article is brought to you for free and open access by the U.S. Department of Defense at DigitalCommons@University of Nebraska - Lincoln. It has been accepted for inclusion in U.S. Navy Research by an authorized administrator of DigitalCommons@University of Nebraska - Lincoln. 


\section{Authors}

Sarah N. Hudson Keenihan, Sutanti Ratiwayanto, Saraswati Soebianto, Krisin, Harijani Marwoto,

Gowdahalli Krishnegowda, D. Channe Gowda, Michael J. Bangs, David J. Frayauff, Thomas L. Richie, Sanjai Kumar, and J. Kevin Baird 


\title{
AGE-DEPENDENT IMPAIRMENT OF IgG RESPONSES TO GLYCOSYLPHOSPHATIDYLINOSITOL WITH EQUAL EXPOSURE TO PLASMODIUM FALCIPARUM AMONG JAVANESE MIGRANTS TO PAPUA, INDONESIA
}

\author{
SARAH N. HUDSON KEENIHAN, SUTANTI RATIWAYANTO, SARASWATI SOEBIANTO, KRISIN, \\ HARIJANI MARWOTO, GOWDAHALLI KRISHNEGOWDA, D. CHANNE GOWDA, MICHAEL J. BANGS, \\ DAVID J. FRYAUFF, THOMAS L. RICHIE, SANJAI KUMAR, AND J. KEVIN BAIRD \\ United States Navy Medical Research Unit 2, Jakarta, Indonesia; Infectious Disease Medical Research Center, Ministry of Health \\ Research and Development, Jakarta, Indonesia; Department of Biochemistry and Molecular Biology, Pennsylvania State University \\ College of Medicine, Hershey, Pennsylvania; United States Naval Medical Research Center, Silver Spring, Maryland
}

\begin{abstract}
Immune responses directed at glycosylphosphatidylinositol (GPI) anchors of Plasmodium falciparum may offer protection against symptomatic malaria. To independently explore the effect of age on generation of the anti-GPI IgG response, we measured serum anti-GPI IgGs in a longitudinal cohort of migrant Javanese children (6-12 years old) and adults ( $\geq 20$ years old) with equivalent numbers of exposures to $P$. falciparum in Papua, Indonesia. While the peak response in adults was achieved after a single infection, comparable responses in children required $\geq 3-4$ infections. Significantly fewer children $(16 \%)$ than adults $(41 \%)$ showed a high (optical density $>0.44)$ anti-GPI IgG response (odds ratio $[\mathrm{OR}]=3.8,95 \%$ confidence interval $[\mathrm{CI}]=2.3-6.3, P<0.0001)$, and adults were more likely to show a persistently high response $(\mathrm{OR}=5.5,95 \% \mathrm{CI}=1.0-56.8, P=0.03)$. However, the minority of children showing a strong response were significantly less likely to experience symptoms with subsequent parasitemia compared with those with a weak response $(\mathrm{OR}=4.0,95 \% \mathrm{CI}=1.1-13.8, P=0.02)$. This effect was not seen among high- and low-responding adults $(\mathrm{OR}=1.2,95 \% \mathrm{CI}=0.5-2.8, P=0.60)$. Host age, independent of cumulative exposure, apparently represents a key determinant of the quantitative and qualitative nature of the IgG response to $P$. falciparum GPI.
\end{abstract}

\section{INTRODUCTION}

Malaria caused by Plasmodium falciparum infection results in death for at least one million people annually. ${ }^{1}$ The inability to diminish the global burden of malaria despite the technological leaps of the past 30 years reflects the broad difficulty of attacking a highly complex parasite impacting the human host across a diverse array of biologic, geographic, social, and economic factors. ${ }^{2}$ Development of a practical vaccine remains a critical technological task in the struggle to contain and diminish morbidity and mortality caused by malaria. ${ }^{3}$ In sub-Saharan Africa, that task focuses on a vaccine that induces a non-sterilizing protection from severe disease among susceptible infants and young children. Adults in this region have naturally acquired protection against clinical disease caused by $P$. falciparum.

Although there is compelling clinical evidence linking class $\mathrm{G}$ immunoglobulins ( $\mathrm{IgG}$ ) with protection against erythrocytic malaria in humans, ${ }^{4-9}$ the precise mechanisms underpinning this correlation remain undefined. Immunoglobulins that bind to proteins expressed at the merozoite surface are thought to prevent normal interactions between parasites and erythrocytes and to initiate parasite destruction, ${ }^{10}$ thereby reducing the overall parasite burden. Antibodies may also prevent symptomatic malaria through preventing the induction of pathologic host inflammation by parasite-derived toxins. Glycosylphosphatidylinositol (GPI) anchors, which represent the major carbohydrate modification in intraerythrocytic $P$. falciparum parasites, ${ }^{11}$ are released into the host blood stream upon rupture of erythrocytic schizonts and in mouse models demonstrate several key properties of a toxin. These include the induction of tumor necrosis factor- $\alpha,{ }^{12}$ interleukin- $1,{ }^{12}$ and nitric oxide ${ }^{13}$ production in macrophages, upregulated adhesion molecule expression in endothelial cells, ${ }^{14}$ and aberrant temperature and glycemic regulation in vivo. ${ }^{12}$ Several of these properties have been blocked with specific antibodies. ${ }^{12-15}$ Furthermore, IgGs induced in mice by vaccination with carrier-conjugated chemically synthesized GPI are associated with protection against malaria acidosis, pulmonary edema, cerebral syndrome, and fatality with severe $P$. berghei malaria. ${ }^{16}$

Three recent studies have addressed the issue of whether anti-GPI immunoglobulins may contribute to anti-toxic immunity in human malaria. The use of highly purified $P$. falciparum-derived GPIs as the target antigen in an enzymelinked immunosorbent assay (ELISA) format resulted in the detection of specific $\operatorname{IgM}^{17,18}$ and $\operatorname{IgG}^{17-19}$ in the plasma and sera of adults and children exposed to endemic or seasonal $P$. falciparum malaria. While the anti-GPI IgG response was found to correlate with protection against malarial anemia and fever in Kenyan children, ${ }^{17}$ no significant relationship between levels of antibodies to GPI and protection against malaria symptoms was found in Kenyan adults ${ }^{17}$ or Gambian children. ${ }^{19}$ However, a consistent finding among these reports was that both the prevalence and concentration of anti-GPI IgG increases in an age-dependent manner. Positive responses were least frequent in those $\leq 5$ years old, increased significantly during older childhood (5-9 years old) and early adolescence (10-14 years old), and peaked in the late teenage (15-19) and adult $(\geq 20)$ years. ${ }^{17-19}$ A similar pattern was observed for GPI-specific IgM responses, although generally these antibodies were much less common than IgGs. ${ }^{18}$ While the possibility has been raised that such age-dependent differences in immunity may be ontogenetic in nature, ${ }^{19}$ it is difficult to directly address this issue by studies of infants, children, and adults having experienced lifelong, heavy exposure to infection. Age correlates directly with cumulative exposure to GPI and other $P$. falciparum antigens in such populations.

We examined the effect of age on the generation of GPIspecific humoral immunity. We had access to a longitudinal cohort of Javanese children and adults exposed to multiple $P$. 
falciparum infections following migration to endemic Indonesian Papua. This study provided unique analytical insight by allowing separation of the effects of age from those of cumulative exposure. The number of infections in this cohort was carefully documented and we compared anti-GPI IgG responses between adults and children having equal exposure to infection.

\section{MATERIALS AND METHODS}

Study site and subjects. A longitudinal study of 243 Javanese migrants (97 children $6-12$ years, and 146 adults aged $\geq 20$ years) to SP2 village in Armopa $\left(139^{\circ} 32^{\prime} \mathrm{E}, 2^{\circ} 16^{\prime} \mathrm{S}\right)$, northeastern Papua, Indonesia (where transmission of $P$. falciparum malaria is perennial) commenced in September 1996, and terminated after 33 months with 168 subjects remaining under routine follow-up. All subjects were enrolled and under observation within 36 hours of arriving in Papua. During the period that virtually all adults in this cohort were born and raised on the island of Java, the available surveillance data suggests the risk of one prior episode of malaria to be less than $0.005 \% .^{20}$ Thus, after careful screening by history of prior residence and the application of other strict inclusion criteria, we considered the subjects to be essentially malarianaïve at enrollment.

Findings presented here represent work performed in accordance with code 32 of Federal Regulation Part 219 (Protection of Human Subjects), U.S. Navy (SECNAVINST 3900.39B) and Ministry of Health, Republic of Indonesia regulations governing the use of human subjects for medical research. The work was reviewed and approved by U.S. Navy and Indonesian committees for protection of human subjects of medical research. Informed consent was obtained from all adult participants and from parents or legal guardians of minors.

Detection and classification of $\boldsymbol{P}$. falciparum infection. All episodes of symptomatic and asymptomatic parasitemia were detected through rigorous and systematic follow-up. This included every two weeks (routine) and symptom-associated (non-routine) blood smear collection, and in-home clinical assessment three times per week. Children and adults experienced qualitatively equal incidence densities of $P$. falciparum parasitemia over the 33-month duration of this study, decreasing from 1.5 infections per person year in the first 12 months to $<1.0$ infections per person year in the latter months (Krisin and others, unpublished data). Positive blood films collected from subjects registering complaints of illness were classified as symptomatic infections and prompted immediate therapy with either chloroquine or mefloquine. This approach almost certainly explains the very low risk of severe malaria in the cohort; only eight subjects required intravenous quinine therapy through the 33 months of follow-up. Parasitemia detected in routine blood films collected from subjects registering no complaint of illness (either by voluntary presentation or scheduled in-home assessment) were classified as asymptomatic infections. A sequence of infections (which included both symptomatic and asymptomatic parasitemias) was constructed for each subject. Venous blood samples collected from subjects at intervals of two months served as the source of convalescent sera for both symptomatic and asymptomatic infections. Convalescence was defined as the period 14-70 days following patent parasitemia.
Quantification of IgG antibodies to GPI by ELISA. Free $P$. falciparum GPI was obtained from mid-schizont stage cultured $P$. falciparum (FCR-3 strain) parasites using rigorous protocols as previously described ${ }^{17}$. Briefly, packed culturederived parasites were lyophilized, extracted in chloroform/ methanol followed by chloroform/methanol/water, dried, and then partitioned between water and water-saturated 1-butanol. The dry residue obtained from the organic layer was extracted with $80 \%$ aqueous 1-propanol, and GPIs were purified by high performance and thin layer chromatography; representative chromatographs have been published previously. ${ }^{17}$ For ELISAs, purified, free GPI was dissolved in methanol, coated $(20 \mathrm{ng} / \mathrm{mL}$ in $100 \mu \mathrm{L})$ onto 96 -well microtiter plates, and used in an ELISA format ${ }^{17}$ for quantification of IgG antibodies to GPI in dilute sera (1:100, in duplicate). The GPI-coated wells containing negative and positive control sera were also analyzed in parallel, as were buffer-coated wells containing control and migrant sera. Negative control sera was collected from $P$. falciparum-naive Indonesian residents of Jakarta and $P$. falciparum-naive, slide-proven $P$. vivax-infected Javanese migrants who had been resident in Papua for 7-19 months and endured two or more prior $P$. vivax infections. Positive control sera were collected from lifelong residents of endemic Papua and Sulawesi, Indonesia. Buffer-coated wells with negative and positive control serum, and migrant serum collected from adults and children at enrolment, and 3-6, 7-12, and > 12 months following enrollment were also included. The levels of anti-GPI IgGs are expressed as the mean measured optical density values $(\lambda=405 \mathrm{~nm})$ for each sample.

Statistical analysis. Non-parametric methods (KruskalWallace analysis of variance [ANOVA] followed by the Mann-Whitney rank sum test) were used to determine the effect of age on anti-GPI OD values at enrollment and the effect of multiple infections on OD values in adults and children, and to compare enrollment OD values with those of negative controls. The effect of age on anti-GPI OD values at each infection was examined by general linear model univariate ANOVA, which used matched enrollment values as a covariate factor. The cut-off for positive and negative values ( 0.44 OD units) was determined by calculation of the mean + $2 \times$ SD of log-transformed enrollment data (since raw data was not normally distributed). The effect of cumulative infection on anti-GPI OD values in subjects with persistently high OD values was examined by general linear model repeated measures ANOVA, which used matched enrollment values as a covariate factor. Results expressing frequencies were compared by Mantel-Haenzel odds ratio (OR) analysis using Cornfield $95 \%$ confidence intervals (CIs) when expected cell values were $>5$, or exact CIs when expected cell values were $\leq 5$. Analysis was carried out using SPSS version 8.0 (SPSS, Inc., Chicago, IL) and Epi-Info version 6 (Centers for Disease Control and Prevention, Atlanta, GA).

\section{RESULTS}

Negligible IgG antibody response to GPI in migrants at enrollment. The OD values were low in most migrants on the day of their enrollment in the study (median $=0.08$ ), although some variability was evident (Figure 1). The enrollment values were not significantly different from those of negative control serum $(P=0.7)$. Enrollment values were 

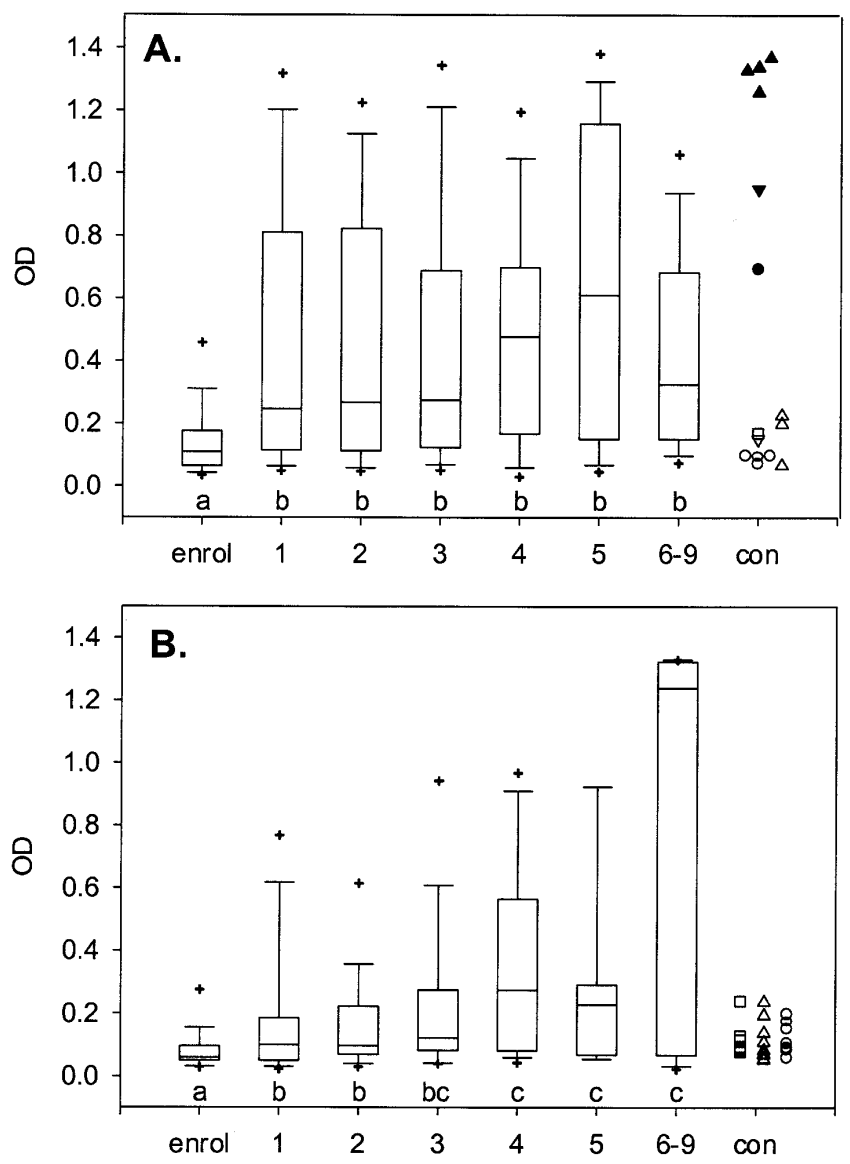

FIgURE 1. Anti-glycosylphosphatidylinositol optical density (OD) values in adults (A) and children (B) at enrollment (enrol) and convalescence of infections $1,2,3,4,5$, and 6-9. Values are shown as medians (horizontal lines) with 25 th-75th percentiles (boxes), 10th90th percentiles (error bars), and 95\% confidence intervals (crosses). Data were compared by Kruskal-Wallis analysis of variance and the Mann-Whitney rank sum test. Groups without common lower case letters on the $\mathrm{x}$-axes are significantly different $(P<0.05)$. Also shown are individual control (con) OD values. Positive controls shown in $\mathbf{A}$ are one lifelong resident of endemic Papua, Indonesia ( $\boldsymbol{\Lambda}$, four individual experiments) and two lifelong residents of endemic Sulawesi, Indonesia ( $\boldsymbol{\nabla}$ and $\bullet)$. Negative controls shown in $\mathbf{A}$ are one male $(O$, four separate experiments) and two female ( $\square$ and $\nabla$ ) lifelong residents of malaria-free Jakarta, Indonesia and three Javanese migrants resident in Papua, Indonesia $(\triangle)$ infected with Plasmodium vivax. Controls shown in $\mathbf{B}$ are OD values derived using buffer-coated wells and serum collected from Javanese migrants after $3-6(\square, \mathrm{n}=9)$, $7-12(\triangle, \mathrm{n}=9)$ and $>12$ months $(O, \mathrm{n}=9)$ residence in Papua, Indonesia.

higher $(P<0.001$; Figure 1$)$ in adults (median $=0.11)$ compared with children (median $=0.06$ ).

Anti-GPI response after a single $P$. falciparum infection. There was a significant effect of a single infection on levels of IgG antibody to GPI. Relative to the median OD value at enrollment in adults, the median value at convalescence 1 in adults increased by 2.3 -fold $(P<0.001$; Figure $1 \mathrm{~A})$. Although less pronounced (increase in median value was only 1.7 -fold), the OD values in children were also significantly increased at convalescence 1 relative to those at enrollment $(P=0.03$; Figure 1B).

Longitudinal anti-GPI IgG response to multiple $P$. falciparum infections in adults and children. We examined the longitudinal effect of 1-9 P. falciparum infections on the $\mathrm{IgG}$ antibody responses to GPI in adults and children separately. As had been seen at infection 1, anti-GPI OD levels were significantly higher in adults at each of infections $2,3,4,5$, and 6-9 compared with their enrollment values $(P \leq 0.001$; Figure $1 \mathrm{~A})$. However, among adults, OD values were not significantly elevated with additional exposure beyond infection 1 $(P>0.4)$.

In children, IgG antibody levels to GPI were also significantly higher at each of infections $2,3,4,5$, and 6-9 compared with their enrollment levels $(P \leq 0.03$; Figure $1 \mathrm{~B})$. Relative to values at infection 1 , there was no significant effect of infections 2 or 3 on levels of $\mathrm{IgG}$ antibody to GPI in children. However, IgG levels were significantly higher at infection 4 compared with both infection $1(P=0.005)$ and infection 2 $(P=0.02)$ in this age group. The IgG levels were not significantly different between infections 3 and 4 , or infection 4 and subsequent infections $(P \geq 0.1)$.

To determine the effect of age on the longitudinal anti-GPI IgG response to $P$. falciparum infection, we compared OD values in adults and children at each individual infection, and used matched enrollment values as a covariate factor. At convalescence of infection $1(P=0.001)$, infection $2(P=0.003)$, and infection $3(P=0.03)$, anti-GPI OD values were significantly higher in adults compared with children (Figure 1). In subsequent infections, there was no significant effect of age on anti-GPI $\operatorname{IgG}(0.80 \geq P \geq 0.08)$.

Effect of age on generation of high anti-GPI IgG responses. It is clear from Figure 1 that although anti-GPI responses tended to be higher overall in adults than in children in infections 1-3, there were some children who appeared capable of mounting an immune response of similar magnitude to responsive adults. We divided subjects into those with high and low anti-GPI IgG responses based on a cut-off value of 0.44 OD units (cut-off calculated as described in the Materials and Methods). Accordingly, 41\% (108 of 263) of all convalescent episodes in adults showed a high anti-GPI IgG response, with the proportion of positive responders increasing from $40 \%$ at infection 1 to $>50 \%$ in infections 4 and 5 (Table 1 ). In contrast, only $16 \%$ (27 of 173 ) of all convalescent sera in children showed a high anti-GPI IgG response (Table 1). Thus, across all infections, adults were nearly four times more likely to have a high anti-GPI IgG response than were children $(\mathrm{OR}=3.8,95 \% \mathrm{CI}=2.3-6.3, P<0.0001)$. This relationship was most clearly evident in early infections, with only $7-12 \%$ of children showing high levels of anti-GPI IgG at infections 1,2 , and $3(0.02 \geq P \geq 0.001$; Table 1$)$. Although a lower proportion of children (13-32\%) than adults $(52-54 \%)$ had a high IgG response in infections 4 and 5 , these differences were not statistically significant $(P \geq 0.06$; Table 1).

We examined the ability to maintain a persistently high anti-GPI IgG titer among children and adults. Among the 106 adults, $57(54 \%)$ had a high anti-GPI IgG response at least once during the course of the study. Seventeen of these 57 subjects had no subsequent episodes of infection and thus offered no further sera for the ELISA. Of the remaining 40 adult subjects, $22(55 \%)$ had persistently high anti-GPI IgG responses. Of the 73 children, 23 individuals (32\%) had a high anti-GPI IgG response at least once during the course of the study. Twelve of those 23 subjects offered no further sera, and 2 of the remaining 11 subjects $(18 \%)$ showed persistently high anti-GPI IgG responses. Thus, compared with children, adults 
TABLE 1

Effect of age on occurrence of high anti-glycosylphosphatidylinositol (GPI) IgG responses at convalescence*

\begin{tabular}{|c|c|c|c|c|c|c|c|c|c|c|c|c|c|c|}
\hline & \multicolumn{2}{|c|}{ Infection 1} & \multicolumn{2}{|c|}{ Infection 2} & \multicolumn{2}{|c|}{ Infection 3} & \multicolumn{2}{|c|}{ Infection 4} & \multicolumn{2}{|c|}{ Infection 5} & \multicolumn{2}{|c|}{ Infections 6-9 } & \multicolumn{2}{|c|}{ All } \\
\hline & A & $\mathrm{C}$ & A & $\mathrm{C}$ & A & $\mathrm{C}$ & A & $\mathrm{C}$ & A & $\mathrm{C}$ & A & $\mathrm{C}$ & A & $\mathrm{C}$ \\
\hline Positive & 37 & 7 & 24 & 3 & 18 & 4 & 15 & 8 & 7 & 1 & 7 & 4 & 108 & 27 \\
\hline Negative & 55 & 52 & 37 & 39 & 32 & 29 & 14 & 17 & 6 & 7 & 11 & 2 & 155 & 146 \\
\hline OR & \multicolumn{2}{|c|}{5.0} & \multicolumn{2}{|c|}{8.4} & \multicolumn{2}{|c|}{4.1} & \multicolumn{2}{|c|}{2.3} & \multicolumn{2}{|c|}{8.2} & \multicolumn{2}{|c|}{0.3} & \multicolumn{2}{|c|}{3.8} \\
\hline $\mathrm{CI}$ & \multicolumn{2}{|c|}{$1.9-13.5$} & \multicolumn{2}{|c|}{$2.2-46.5$} & \multicolumn{2}{|c|}{$1.1-18.2$} & \multicolumn{2}{|c|}{$0.7-8.1$} & \multicolumn{2}{|c|}{$0.6-419.5$} & \multicolumn{2}{|c|}{$0.02-3.1$} & \multicolumn{2}{|c|}{$2.3-6.3$} \\
\hline$P$ & \multicolumn{2}{|c|}{0.001} & \multicolumn{2}{|c|}{$<0.001$} & \multicolumn{2}{|c|}{0.02} & \multicolumn{2}{|c|}{0.14} & \multicolumn{2}{|c|}{0.06} & \multicolumn{2}{|c|}{0.2} & \multicolumn{2}{|c|}{$<0.001$} \\
\hline
\end{tabular}

* Positive and negative values are numbers of adult (A) and child (C) subjects with high (optical density $[\mathrm{OD}]>0.44)$ and low $(\mathrm{OD} \leq 0.44)$ anti-GPI IgG responses at convalescence of infections 1-9. Odd ratio (OR), Cornfield $95 \%$ confidence interval (CI), and $P$ values are for a positive response in adults versus children.

were 2.5 times more likely to record at least one positive anti-GPI $\mathrm{IgG}$ response (95\% CI $=1.3-5.0, P=0.003)$, and almost six times more likely to have persistently high antiGPI IgG responses $(\mathrm{OR}=5.5,95 \% \mathrm{CI}=1.0-56.8, P=0.03)$ with 1-9 $P$. falciparum infections. There was no significant effect of cumulative infection on anti-GPI OD values among persistently high subjects $(P=0.4)$.

Anti-GPI response and risk of symptoms in subsequent infection. There were respectively 194 and 117 convalescent samples available from adults and children who endured one or more subsequent $P$. falciparum infections. By classifying each of these infections as symptomatic or asymptomatic (as described in the Materials and Methods), we analyzed the relationship between occurrence of a high anti-GPI IgG response and absence of symptoms in the immediately subsequent infection. Among adults, 19\% (14 of 72) of high and $16 \%$ (20 of 122) of low anti-GPI IgG convalescent values were immediately followed by an asymptomatic infection. Thus no correlation appeared for the risk of symptoms with new infection following prior occurrence of a high anti-GPI $\mathrm{IgG}$ response in adults $(\mathrm{OR}=1.2,95 \% \mathrm{CI}=0.5-2.8, P=$ $0.60)$. Children with a high anti-GPI IgG response were significantly more likely to be asymptomatic in the immediately subsequent infection $(41 \%, 7$ of 17$)$ than children with a low response $(15 \%, 15$ of $100 ; \mathrm{OR}=4.0,95 \% \mathrm{CI}=1.1-13.8$, $P=0.02)$.

\section{DISCUSSION}

The GPI anchors of $P$. falciparum may play a role in the pathogenesis of malaria. Here we present the results of a longitudinal analysis of anti-GPI IgG in convalescent serum of adults and children following migration from Java to hyperendemic northeastern Indonesian Papua. The quantitatively equal incidence densities of $P$. falciparum parasitemia among children and adults over the 33-month duration of this study, and the sequencing of episodes of parasitemia among subjects allowed us to examine the effect of age on the immune response independent of differences in cumulative exposure that normally occur among lifelong residents of endemic areas. This analysis demonstrated impaired onset of anti-GPI IgG, diminished peak levels, and weak persistence of that response among children compared with adults. Moreover, elevated anti-GPI IgG correlated with diminished risk of fever among children but not adults. Host age, independent of the effects of cumulative exposure, affected both the quantitative and qualitative nature of the humoral immune response to GPI of $P$. falciparum.

Many studies of childhood malaria focus on children 0-3 years old, since it is this age group that bears the burden of childhood malaria in endemic Africa. ${ }^{17,20,21}$ Furthermore, it has been proposed that children $\leq 2-3$ years old and exposed to heavy infective pressure since birth exhibit a unique form of anti-toxic immunity that results in their relatively high fever threshold despite high parasite densities. ${ }^{20}$ This phenomenon was not the focus of the work presented here. Instead, we directed our investigation towards older children $(\geq 6-12$ years old) to determine whether previous descriptions of maturation-dependent, sub-optimal development of clinical protection against malaria in this particular age group in Papua $^{20,22}$ and Africa ${ }^{23}$ were reflected in immune parameters.

Our findings with anti-GPI IgG argue in favor of intrinsic age-dependent factors as determinants of the immune response to falciparum malaria. ${ }^{20,22,23}$ The results are also consistent with those reported from populations having lifelong heavy exposure to infection. ${ }^{17-19}$ Such distinctions are usually ascribed to differences in cumulative exposure to infection, with an optimal immune response thought to correspond with superior experience of the antigenic repertoire of the parasite. ${ }^{24,25}$ Even if an extrinsic factor like exposure to diverse antigens drives age-dependent differences in humoral immune responses to some antigens of falciparum malaria, one may not expect to observe such an outcome with responses to GPI. GPI molecules have been shown to have remarkable structural consistency, perhaps even identity, between $P$. falciparum isolates from four continents. ${ }^{26}$

That adults showed slightly higher background levels in our ELISA is not unique. In confirming the specificity of their GPI ELISA (which was the same as that used in our assays), Naik and others found that rural Kenyan adult sera have background levels of reactivity to common acylated phosphoglycerols, a phenomenon attributed to the propensity of polyclonal antibodies to react with common epitopes. ${ }^{17}$ Given that our study subjects had migrated from predominantly rural areas, it would seem likely that their sera would also contain some cross-reactive antibodies, and perhaps this explained the occasional high OD values that were noted in some adults and fewer children on the day of enrollment in our study. Rather than apply a selection bias and exclude subjects with high background readings, by including matched enrollment values as a covariate factor we were able to show that despite differences in enrollment values, anti-GPI IgG responses were still significantly higher in adults compared with children. We also found similar background OD values in 18 serum samples collected 3-6, 7-12, and >12 months following enrollment, suggesting that the capacity of serum to stick non-specifically to the ELISA plates did not change over the 33 months of the study period. 
It has long been recognized that overall titers of IgG antibodies, especially of subclasses IgG2 and IgG4, are lower in infants and pre-pubescent children compared with adults. ${ }^{27,28}$ While poor anti-GPI responses in young children have been suggested to result from an inability of neonates and infants less than two years old to make substantial IgG responses to carbohydrate or glycolipid antigens, ${ }^{19}$ differences in immunity between older children and adults remain relatively unexplored. Kurtis and others hypothesize that the onset of puberty, indicated by increased circulating levels of hormones such as dehydroepiandrosterone sulfate, somehow induces in children the capacity to mount adult-like immune responses to malaria. ${ }^{23}$ A similar hypothesis has been proposed to explain age-dependence in immunity against schistosomiasis. ${ }^{29}$ However, the exact mechanism explaining age-dependence in generation of antigen-specific immunity in malaria remains unknown at this time.

In conclusion, we have demonstrated host age as a determinant that acts independently of cumulative exposure in generation of anti-GPI IgG responses in Javanese migrants to Indonesian Papua. If indeed older children cannot mount protective immune response specific to toxins such as GPI, this could provide some clue as to why, relative to adults, this age group is predisposed to increased clinical illness with chronic $P$. falciparum infection. ${ }^{30}$ The relative contributions of intrinsic factors such as host age and of extrinsic factors such as antigenic diversity to the onset of clinical immunity to falciparum malaria constitute a question of core importance to strategies for developing vaccines intended to diminish morbidity and mortality among young African children.

Received January 6, 2003. Accepted for publication April 2, 2003.

Acknowledgments: We express our gratitude for the contributions of the following people to this study: Dr. Budi Subianto, Dr. Hendra Wijaya, Sugoto, Suradi Wangsamuda, Moch Sutamiharja, Tiot Karubuy, Supriyanto, Ferryanto Sangganele, Sunardi, Jumhan Anis, Willem Burdam, and the Papuan health workers. We also acknowledge the Ministry of Health Research and Development, Republic of Indonesia for its support in making this work possible, with special thanks to Dr. Sri Astuti, Dr. Sumarijati Arjoso and Dr. Ingerani. This work was presented in part at the 50th Annual Meeting of the American Society of Tropical Medicine and Hygiene, Atlanta, GA, November 2001.

Financial support: This work was supported by the U.S. Department of Defense, Military Infectious Diseases Research Program under STO F (malaria vaccine development).

Disclaimer: The views of the authors are their own and do not purport to represent those of the U.S. Navy or the Department of Defense.

Authors' addresses: Sarah N. Hudson Keenihan, Department of Obstetrics and Gynaecology, 6th Floor Medical School North Wing, Frome Road, Adelaide, SA 5005, Australia, Telephone: 61-8-83035100, Fax: 61-8-8303-4099, E-mail: sarah.hudson-keenihan@ adelaide.edu.au. Sutanti Ratiwayanto, Saraswati Soebianto, Krisin, and Michael J. Bangs, c/o Commanding Officer, United States Naval Medical Research Unit 2, American Embassy Jakarta, FPO AP 96520 USA, Telephone: 62-21-421-4457, Fax: 62-21-424-4507. J. Kevin Baird, Naval Medical Research Center Detachment, Unit 3800, American Embassy Lima, Lima, Peru APO AA 34031, Telephone: Fax: 51-1-561-3042, E-mail: baird@nmrcd.med.navy.mil. Harijani Marwoto, P2PLP, Kompleks Balitbangkes Jl., Percetakan Negara No. 29, Jakarta 10570 Indonesia, Telephone: 62-21-426-1088 extension 157, Fax: 62-21-424-3933. Gowdahalli Krishnegowda and D. Channe Gowda, Department of Biochemistry and Molecular Biology, H171, College of Medicine, Room C5710, Pennsylvania State University, 500 University Drive, Hershey, PA 17033, Telephone:
717-531-0992, Fax: 717-531-7072. David J. Fryauff, Malaria Program, Naval Medical Research Center, 503 Robert Grant Avenue, Silver Spring, MD 20910-7500, Telephone: 301-319-7583, Fax: 301-319-7545. Thomas L. Richie, Malaria Program, Naval Medical Research Center, 503 Robert Grant Ave, Silver Spring, MD 20910-7500, Telephone: 301-295-0007, Fax: 301-319-7545. Sanjai Kumar, Center for Biologics Evaluation and Research, Food and Drug Administration, Rockville, MD 20857, Telephone: 301-827-1800, Fax: 301-827-4622.

Reprint requests: Commanding Officer, United States Navy Medical Research Unit 2, American Embassy Jakarta, FPO AP 96520 USA, Attn: Publications Office.

\section{REFERENCES}

1. Greenwood B, Mutabingwa T, 2002. Malaria in 2002. Nature 415: 670-672.

2. Miller LH, Baruch DI, Marsh K, Doumbo OK, 2002. The pathogenic basis of malaria. Nature 415: 673-679.

3. Richie TL, Saul A, 2002. Progress and challenges for malaria vaccines. Nature 415: 694-701.

4. Cohen S, McGregor IA, Carrington S, 1961. Gamma globulin and acquired immunity to malaria. Nature 192: 773-777.

5. Edozien JC, Gilles HM, Udezo IOK, 1962. Adult and cord-blood gamma-globulin and immunity to malaria in Nigerians. Lancet ii: 951-955.

6. McGregor IA, 1964. The passive transfer of human malarial immunity. Am J Trop Med Hyg 13: 237-239.

7. McGregor IA, Carrington S, Cohen S, 1963. Treatment of east African Plasmodium falciparum malaria with west African human gamma globulin. Trans R Soc Trop Med Hyg 57: 170-175.

8. Bouharoun-Tayoun H, Attanath P, Sabchareon A, Chongsuphajaisiddhi T, Druilhe P, 1990. Antibodies that protect humans against Plasmodium falciparum blood stages do not on their own inhibit parasite growth and invasion in vitro, but act in cooperation with monocytes. J Exp Med 172: 16331641.

9. Sabchareon A, Burnouf T, Ouattara D, Attanath P, BouharounTayoun H, Chantavanich P, Foucault C, Chongsuphajaisiddhi T, Druilhe P, 1991. Parasitologic and clinical human response to immunoglobulin administration in falciparum malaria. Am J Trop Med Hyg 45: 297-308.

10. Ramasamy R, Ramasamy M, Yasawardena S, 2001. Antibodies and Plasmodium falciparum merozoites. Trends Parasitol 17: 194-197.

11. Gowda DC, Gupta P, Davidson EA, 1997. Glycosylphosphatidylinositol anchors represent the major carbohydrate modification in proteins of intraerythrocytic stage Plasmodium falciparum. J Biol Chem 272: 6428-6439.

12. Schofield L, Hackett F, 1993. Signal transduction in host cells by a glycosylphosphatidylinositol toxin of malaria parasites. $J$ Exp Med 177: 145-153.

13. Tachado SD, Gerold P, McConville MJ, Baldwin T, Quilici D, Schwarz RT, Schofield L, 1996. Glycosylphosphatidylinositol toxin of Plasmodium induces nitric oxide synthase expression in macrophages and vascular endothelial cells by a protein tyrosine kinase-dependent and protein kinase C-dependent signaling pathway. J Immunol 156: 1897-1907.

14. Schofield L, Novakovic S, Gerold P, Schwarz RT, McConville MJ, Tachado SD, 1996. Glycosylphosphatidylinositol toxin of Plasmodium up-regulates intercellular adhesion molecule-1, vascular cell adhesion molecule-1, and E-selectin expression in vascular endothelial cells and increases leukocyte and parasite cytoadherence via tyrosine kinase-dependent signal transduction. J Immunol 156: 1886-1896.

15. Schofield L, Vivas L, Hackett F, Gerold P, Schwarz RT, Tachado S, 1993. Neutralizing monoclonal antibodies to glycosylphosphatidylinositol, the dominant TNF-alpha-inducing toxin of Plasmodium falciparum: prospects for the immunotherapy of severe malaria. Ann Trop Med Parasitol 87: 617-626.

16. Schofield L, Hewitt MC, Evans K, Siomos M, Seeberger PH, 2002. Synthetic GPI as a candidate anti-toxic vaccine in a model of malaria. Nature 418: 785-789.

17. Naik RS, Branch OH, Woods AS, Vijaykumar M, Perkins DJ, Nahlen BL, Lal AA, Cotter RJ, Costello CE, Ockenhouse CF, 
Davidson EA, Gowda DC, 2000. Glycosylphosphatidylinositol anchors of Plasmodium falciparum: molecular characterization and naturally elicited antibody response that may provide immunity to malaria pathogenesis. J Exp Med 192: 1563-1576.

18. Boutlis CS, Gowda DC, Naik RS, Maguire GP, Mgone CS, Bockarie MJ, Lagog M, Ibam E, Lorry K, Anstey NM, 2002. Antibodies to Plasmodium falciparum glycosylphosphatidylinositols: inverse association with tolerance of parasitemia in Papua New Guinean children and adults. Infect Immun 70: 5052-5057.

19. De Souza JB, Todd J, Krishegowda G, Gowda DC, Kwiatkowski D, Riley EM, 2002. Prevalence and boosting of antibodies to Plasmodium falciparum glycosylphosphatidylinositols and evaluation of their association with protection from mild and severe clinical malaria. Infect Immun 70: 5045-5051.

20. Baird JK, 1995. Host age as a determinant of naturally acquired immunity to Plasmodium falciparum. Parasitol Today 11: 105111.

21. McGregor IA, 1987. The significance of parasitic infections in terms of clinical disease: a personal view. Parasitology 94 (Suppl): S159-S178.

22. Baird JK, 1998. Age-dependent characteristics of protection v. susceptibility to Plasmodium falciparum. Ann Trop Med Parasitol 92: 367-390.
23. Kurtis JD, Mtalib R, Onyango FK, Duffy PE, 2001. Human resistance to Plasmodium falciparum increases during puberty and is predicted by dehydroepiandrosterone sulfate levels. Infect Immun 69: 123-128.

24. Day KP, Marsh K, 1991. Naturally acquired immunity to Plasmodium falciparum. Immunol Today 12: A68-A71.

25. Snow RW, Marsh K, 1998. New insights into the epidemiology of malaria relevant for disease control. Br Med Bull 54: 293-309.

26. Berhe S, Schofield L, Schwarz RT, Gerold P, 1999. Conservation of structure among glycosylphosphatidylinositol toxins from different geographic isolates of Plasmodium falciparum. Mol Biochem Parasitol 103: 273-278.

27. Morell A, Skvaril F, Hitzig WH, Barandun S, 1972. IgG subclasses: Development of the serum concentrations in "normal" infants and children. J Pediatr 80: 960-964.

28. Oxelius V, 1979. IgG subclass levels in infancy and childhood. Acta Paediatr Scand 68: 23-27.

29. Fulford AJC, Webster M, Ouma JH, Kimani G, Dunne DW, 1998. Puberty and age-related changes in susceptibility to schistosome infection. Parasitol Today 14: 23-26.

30. Baird JK, Masbar S, Basri H, Tirtokusumo S, Subianto B, Hoffman SL, 1998. Age-dependent susceptibility to severe disease with primary exposure to Plasmodium falciparum. J Infect Dis 178: $592-595$. 